\title{
Cutting temperature measurement in turning of thermoplastic composites using a tool-work thermocouple
}

\author{
Petr Masek ${ }^{1}$ (D) Pavel Zeman ${ }^{1} \cdot$ Petr Kolar $^{2}$ \\ Received: 1 March 2021 / Accepted: 24 June 2021 / Published online: 17 July 2021 \\ (C) The Author(s), under exclusive licence to Springer-Verlag London Ltd., part of Springer Nature 2021
}

\begin{abstract}
Turning of carbon fibre reinforced thermoplastic pipes is used for production of fluid ducts for the aerospace and oil industries. Although thermoplastics are chemically stable, the matrix could be affected by the heat introduced by the machining process. This paper presents how to measure cutting temperature using C/PEEK and C/PA12 material as examples. A suitable method based on a thermocouple circuit and electric conductivity of the carbon fibres is presented, including system calibration. Measurement uncertainties were established for this new method of calibration and measurement for both tested materials. The cutting temperature measurements were analysed by ANOVA and significant factors and its dependence on temperature were identified for further machining process optimization and determination of the predictive model equation. This mathematical cutting temperature model was estimated based on the measurements, and empirical coefficients were identified for selected statistically significant parameters for both composite materials. Because the measured temperatures were above the melting point, the machined surface, chips and structural changes of polymeric matrices were measured in order to prove heat affection.
\end{abstract}

Keywords Thermoplastic composites · Turning · Cutting temperature measurement

\section{Introduction}

Increasing the useful properties of the structural element is essential for improving product design. One way to achieve this is to reduce the part's weight when its mechanical properties are fixed or improved by a combination of two or more different types of construction materials. Materials with two or more components are called composites and combine the properties of a reinforcement and the properties of the matrix. Polymer composites with fibre reinforcement are suitable for construction parts under low stress or structural elements of machines mainly for decreasing the entire weight of a product

Petr Masek

P.Masek@rcmt.cvut.cz

1 Department of Production Machines and Equipment, Faculty of Mechanical Engineering, Center of Advanced Aerospace Technology, Czech Technical University in Prague, Technicka Street 4, 16607 Prague 6, Czech Republic

2 Research Center of Manufacturing Technology, Department of Production Machines and Equipment, Faculty of Mechanical Engineering, Czech Technical University in Prague, Horska 2, 128 00 Prague 2, Czech Republic
[1]. The fibres of reinforcements are typically glass, carbon or natural. Polymer matrices are thermosets or thermoplastics. The choice of matrix and fibre type, the matrix-fibre volume ratio and the orientation of the reinforcement in the composite influence the resulting mechanical properties as well as workpiece machinability. The most commonly used combinations are glass or carbon fibres in the thermoset matrix [2].

Thermoplastic matrices are used less often than composites with a resin matrix. Thermoplastic matrices have some technological advantages, including, for example, the possibility of post-process hot forming and better recyclability [3]. Thermoplastic composites have better machinability in comparison to thermosets because fewer dust particles are produced during machining and there is a lower tendency to delamination [4]. Thermoplastics with carbon fibres are used in the aircraft and automotive industries but they have also penetrated other sectors of industry. The entire processing chain of composite parts was described by Fleischer [5]. One of the main problems of composite parts is quality after machining. Thermoplastic composites are machined to achieve dimensional and shape accuracy or to prepare functional surfaces. Quality problems, such as delamination, thermal influence of the machined surface or surface roughness, are discussed through all types of machining technologies, e.g. [6-9]. The 
quality can be monitored in the process indirectly by measuring the cutting force, the cutting temperature and the wear of the cutting tool, if the relationship between these quantities and the evaluated surface quality is known. Mechanical loads can be reduced by reducing cutting force through cutting conditions, especially feed, and then also by optimizing the tool geometry. The heat generation is also affected by the geometry of the cutting tool, but mainly also by the cutting speed. Due to the low thermal conductivity of polymer matrices, the heat concentration at the cutting edge can be a serious problem for the quality of the machined surface.

Thermoplastic composites are machined in order to obtain dimensional and shape accuracy or to prepare functional surfaces Drilling operations are used for preparing of holes for joining. It is the most commonly used cutting technology for machining composite parts and has been researched in many studies. They focus mainly on the quality of enter and exit of the hole, e.g. [10-12], but a smaller amount is also focused on measuring the temperature during drilling, e.g. [13-15]. The second widely used cutting technology is milling. Composite part milling is used to trim composite surpluses at the edges of the part after forming. Milling technology studies are very often focused on delamination and how to prevent it, e.g. [16-18]. Temperature is studied only marginally, e.g. [19, 20]. Turning of the composite rods or pipes is widely used for creating recess at the end of workpieces. Composite pipes are used in the aircraft, energetic or petrochemical industry for the conduction of fluids usually such as fuel or coolants [21]. Some of these pipes are winded in multidirectional layers.

Ferreira studied turning of CFRP (Carbon Fibre Reinforced Plastics) with a fibre content of $40 \%$ and phenolic resin [22]. His work revealed the dependency of the cutting speed on cutting tool wear. He tested various cutting materials and found out that cemented carbide had flank wear of $1.5 \mathrm{~mm}$ after machining a length of $600 \mathrm{~mm}$, while the PCD showed only $0.05 \mathrm{~mm}$ after a $1400-\mathrm{mm}$ distance. Rahman machined by turning CFRP in his work and studied cutting tool wear for different types of material while the cutting speed was 80 $\mathrm{m} / \mathrm{min}$ in maximum [23]. In accordance with previous studies, he evaluated cemented carbides as unsuitable for turning of this material.

Sreejith measured the influence of cutting conditions on the machining temperature by optical pyrometer [24]. The critical cutting speed was identified as $300 \mathrm{~m} / \mathrm{min}$ in this study. The considerable increasing variability of the measured values was above this critical value. Davim studied turning of PEEK thermoplastic composite with a $30 \%$ carbon fibre content from the perspective of cutting forces [25]. A cutting tool with a positive rake angle had less steep cutting force dependence on the feed in comparison with a cutting tool with a rake angle of $0^{\circ}$. The tool with the positive rake angle had approximately $30 \%$ lower feed force in comparison. Mata tested the influence of cutting conditions on C/PEEK composite with various fibre contents in a subsequent study [26]. It was found that machinability deteriorated when cutting velocity ranged from 50 to $200 \mathrm{~m} / \mathrm{min}$ and feed from 0.05 to $0.2 \mathrm{~mm}$. Mata dealt with cutting force prediction models using a regression analysis for machining of C/PEEK in his next study [27]. Dold used tools with laser manufactured geometry during turning of CFRP [28]. He focused on observation of differences between ground and laser machined geometry for various directions of wound composites and he measured cutting forces and surface roughness. A higher feed force was observed for a laser machined cutting tool, but surface roughness was lower in comparison with a ground cutting edge.

It is essential to understand the influence of cutting temperature on surface quality due to the very low melting point of the polymeric matrix when composite is machined. Above the melting point, it is possible to observe a steep decrease in mechanical properties, manifested by decreasing cutting force [24]. The temperature increases considerably locally in the shear zone between the cutting tool and the composite material because the polymeric matrices are poor heat conductors. This temperature can be called the cutting temperature. The cutting temperature is the average temperature of all contact points between the cutting tool and the workpiece. This temperature can be measured with a tool-work (natural) thermocouple. This thermocouple arises between the material of the cutting tool and the material of the workpiece due to their different electric potentials when the cold junction and hot junction have different temperatures. Other temperature measurement methods cannot determine cutting temperature, but rather the temperature of the point where the detector was placed or the temperature field. Davies summarized various temperature measurement methods during machining [29].

Kerrigan used an embedded (artificial) thermocouple in a cutting tool during milling operations [30]. This measurement method had a time delay in recording due to the mass of the cutting tool material between the shear zone and a K-type thermocouple placed in the cutting tool. It is disadvantageous for short-time measurement. Wang used a semi-artificial thermocouple during milling [31]. He put a thin constantan sheet between two CFRP boards. Wang observed a degradation of the resin during higher cutting speeds. The degraded resin did not support fibres well and they were easily pulled out. Masek used a similar temperature measurement principle during milling of C/PPS but using Ni-Cr wires [32]. A temperature point measurement proved that the glass transition temperature had been exceeded for all measurements in the cutting velocity ranging from 100 to $300 \mathrm{~m} / \mathrm{min}$. No degradation of the matrix was observed either on the chips or on the machined surface. Merino-Pérez introduced contactless measurement with an infrared camera on the hole exit during drilling [15]. He measured the temperature in the maxima of $250{ }^{\circ} \mathrm{C}$ and did not observe any thermal damage to the matrix. Sheik-Ahmad used an infrared camera during milling as well [33]. He compared 
three different burr cutters and their influence on machining of CFRP and found that with increasing feed, more heat went to the chips due to increasing chip thickness. Yoshiro used a work-tool thermocouple during milling [34]. He observed that the glass transition temperature was exceeded for a cutting speed as low as $25 \mathrm{~m} / \mathrm{min}$. His measurement was supported with infrared camera measurement. No matrix damage was found when the machined surfaces were observed with an electron microscope.

There has been only a limited extent of experimental measurement with tool-work thermocouples during turning in machining technology, and it has been used solely for machining of metal workpieces. This method is well described for metal materials in terms of calibration as well as method measurement. The measurement itself is limited due mainly to the relatively complicated transmission of the EMF signal from the rotary to the stationary part of the thermocouple circuit. In earlier times, the signal was conducted with friction tips which had a different chemical composition than the workpiece material $[35,36]$. The friction generates heat, which is conducted in the circuit of the thermocouple as the parasitic EMF signal which needs to be compensated. A more sophisticated method is to use rotation translation in a mercury bath [37-39]. The advantage of this method is parasitic signal prevention in this critical part of the thermoelectric circuit. The magnitude of the resulting EMF signal is very small and compensation or prevention of the parasitic signal is essential. The circuit must be electrically insulated from all other parts of the machine tool because induction voltage emerges in various parts of the machine tool. A problematic part is the contact of the cutting tool insert and the insert holder, which must also be insulated. This paper also addresses how to resolve this issue with cutting temperature measurement.

Electromotive force (EMF) is measured by thermocouples. EMF is the voltage which is created in the closed thermoelectric circuit between two heated materials with different electric potentials according to the Seebeck phenomena. The right temperature value must be assigned to the EMF experimentally by the calibration measurement. Calibration is valuable only for one pair of thermocouple materials. Usually the calibration is made under a flame [39], in an oven [35, 38] or in a melted metal bath [40]. The most common method is to use a special calibration setup. Calibration under a torch flame uses a metal plate as a mediator for heat conduction from the flame to the contact of a calibrated pair of metals for uniform heat conduction [41]. The temperature of the mediator plate is measured during calibration. Polymeric composites with a low matrix melting point must be heated carefully to avoid damage to the composite matrix and disconnection of the thermoelectric circuit. The design of a suitable calibration method for C/PEEK and C/PA12 materials is an important part of this paper.
The choice of cutting conditions should be conditional on reaching maximum productivity with retention of the quality parameters. Thermal damage is inadmissible during composite machining, although it has not been proven if exceeding the glass transition temperature or melting point has a significant influence on the machined surface quality after turning. This study aims on this issue as well as on the applicability of the chosen method of temperature measurement. This study focuses on the influence of the cutting conditions and cutting tool geometry on the cutting temperature when composites with a thermoplastic matrix are turned with respect to thermal effects on the machined surface. A mathematical model of the cutting temperature with significant parameters such as cutting velocity and tool geometry is presented here as well. The chosen method of the measurement was tool-work thermocouple because this only method can measure the cutting temperature. This work presents a proposal for measuring a toolwork thermocouple and a method for calibrating a tool-work thermocouple.

\section{Design of experiment}

\subsection{Work material and cutting tool description}

The experiment was designed for turning two types of composite materials with a thermoplastic matrix and carbon fibres, marked as C/PEEK and C/PA12. Composites were wound on a rod in tape form. Both composites had the same volume of the identical reinforcement. The properties of both materials are presented in Table 1.

The experimental setup was designed for orthogonal infeed turning of discs with a thickness of $4 \mathrm{~mm}$. Both work materials were machined using a turning indexable insert TPGN type with triangle shape and with rake angle of $0^{\circ}$ and clearance angle $11^{\circ}$. The inserts were processed with picosecond laser equipment to obtain various cutting edge geometries. The inserts were designed with rake angles of $0^{\circ}, 10^{\circ}$ and $20^{\circ}$ and a clearance angle of $11^{\circ}$ (Table 2). The cutting material was micrograin cemented carbide grade TH10 (chemical composition in volume percentages: WC (92\%); $\mathrm{NbC}+\mathrm{TaC}(2 \%)$; $\mathrm{Co}(6 \%))$. No coating was used. The inserts were clamped in a CTFPR tool holder, which is used for an end cutting with the $\mathrm{C}$ type clamping of the insert using the optional chipbreaker (Fig. 1), which had a grounded bed with an inclination of $5^{\circ}$ for the rake angle. Thus, the resulting rake angles were $5^{\circ}, 15^{\circ}$ and $25^{\circ}$.

The real geometry of the inserts was inspected using an Alicona InfiniteFocus G5 scanning digital microscope. The cutting edge radius and surface roughness of the chipbreakers were measured as well. The difference between the measured and designed geometry was negligible and these differences did not affect the measurements. 
Table 1 Material properties of specimens

\begin{tabular}{|c|c|c|c|}
\hline Property & Unit & \multicolumn{2}{|l|}{ Value } \\
\hline \multicolumn{4}{|l|}{ Reinforcement T700 (catalogue values) } \\
\hline Diameter $\left(\mathrm{d}_{\mathrm{f}}\right)$ & $\mu \mathrm{m}$ & \multicolumn{2}{|l|}{7} \\
\hline Tensile strength (Rm) & $\mathrm{MPa}$ & \multicolumn{2}{|l|}{4900} \\
\hline Elongation $(\varepsilon)$ & $\%$ & \multicolumn{2}{|l|}{2.1} \\
\hline Tensile strength modulus (E) & $\mathrm{GPa}$ & \multicolumn{2}{|l|}{230} \\
\hline Density $(\rho)$ & $\mathrm{g} / \mathrm{cm}^{3}$ & \multicolumn{2}{|l|}{1.8} \\
\hline \multicolumn{4}{|l|}{ Matrix (catalogue values) } \\
\hline & & PA12 & PEEK \\
\hline Glass transition temperature $\left(\mathrm{T}_{\mathrm{g}}\right)$ & ${ }^{\circ} \mathrm{C}$ & $40-45$ & 143 \\
\hline Melting point $\left(\mathrm{T}_{\mathrm{m}}\right)$ & ${ }^{\circ} \mathrm{C}$ & 190 & 343 \\
\hline Tensile strength $(\mathrm{Rm})$ & $\mathrm{MPa}$ & 45 & 90 \\
\hline Elongation $(\varepsilon)$ & $\%$ & 300 & 10 \\
\hline Tensile strength modulus (E) & $\mathrm{GPa}$ & 1.6 & 3.65 \\
\hline Thermal conductivity $(\mathrm{k})$ & $\mathrm{W} / \mathrm{m} \mathrm{K}$ & 0.23 & 0.25 \\
\hline Density $(\rho)$ & $\mathrm{g} / \mathrm{cm}^{3}$ & 1.02 & 1.3 \\
\hline \multicolumn{4}{|c|}{ Mechanical properties of composite tapes with T700 reinforcement } \\
\hline & & PA12 & PEEK \\
\hline Short beam shear strength (SBS) & $\mathrm{MPa}$ & 40 & 90 \\
\hline Tensile strength (G12) & $\mathrm{MPa}$ & 1650 & 4650 \\
\hline Adhesive fracture energy $\left(G_{1 c}\right)$ & $\mathrm{kJ} / \mathrm{m}^{2}$ & 0.83 & 1.32 \\
\hline Longitudinal elastic modulus (E1) & $\mathrm{MPa}$ & 133 & 142 \\
\hline Reinforcement volume & $\%$ & 55 & \\
\hline Layer angle of winding on the tube & $\circ$ & \pm 65 & \\
\hline
\end{tabular}

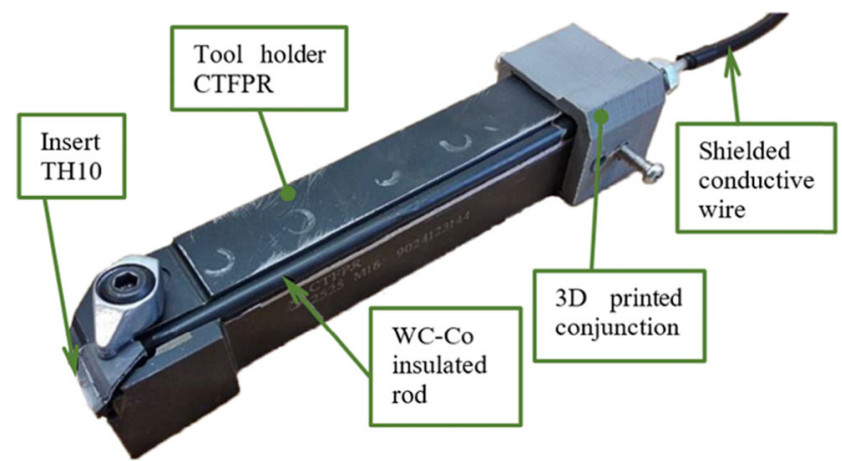

Fig. 1 Modified CTFPR tool holder with 3D printed conjunction

The cutting insert holder had to be modified to decrease the parasitic EMF signal risk (Fig. 1). A carbide rod with a chemical composition similar to the indexable insert was put into the milled groove to avoid the parasitical EMF signal. The carbide rod was pushed against the insert with a screw and spring through which a wire with a small soldered ball on the end was pulled. A clamping device, which held a pushing screw, was printed by FFF from PETG polymer.

\subsection{Experimental setup and cutting temperature evaluation}

Turning tests were performed on a CNC lathe with a horizontal axis with a maximum spindle speed of $3150 \mathrm{~min}^{-1}$, maximum power of $42 \mathrm{~kW}$, maximum turning diameter of $550 \mathrm{~mm}$ and maximum turning length of $2500 \mathrm{~mm}$. The schematic

Table 2 Carbide indexable insert parameters

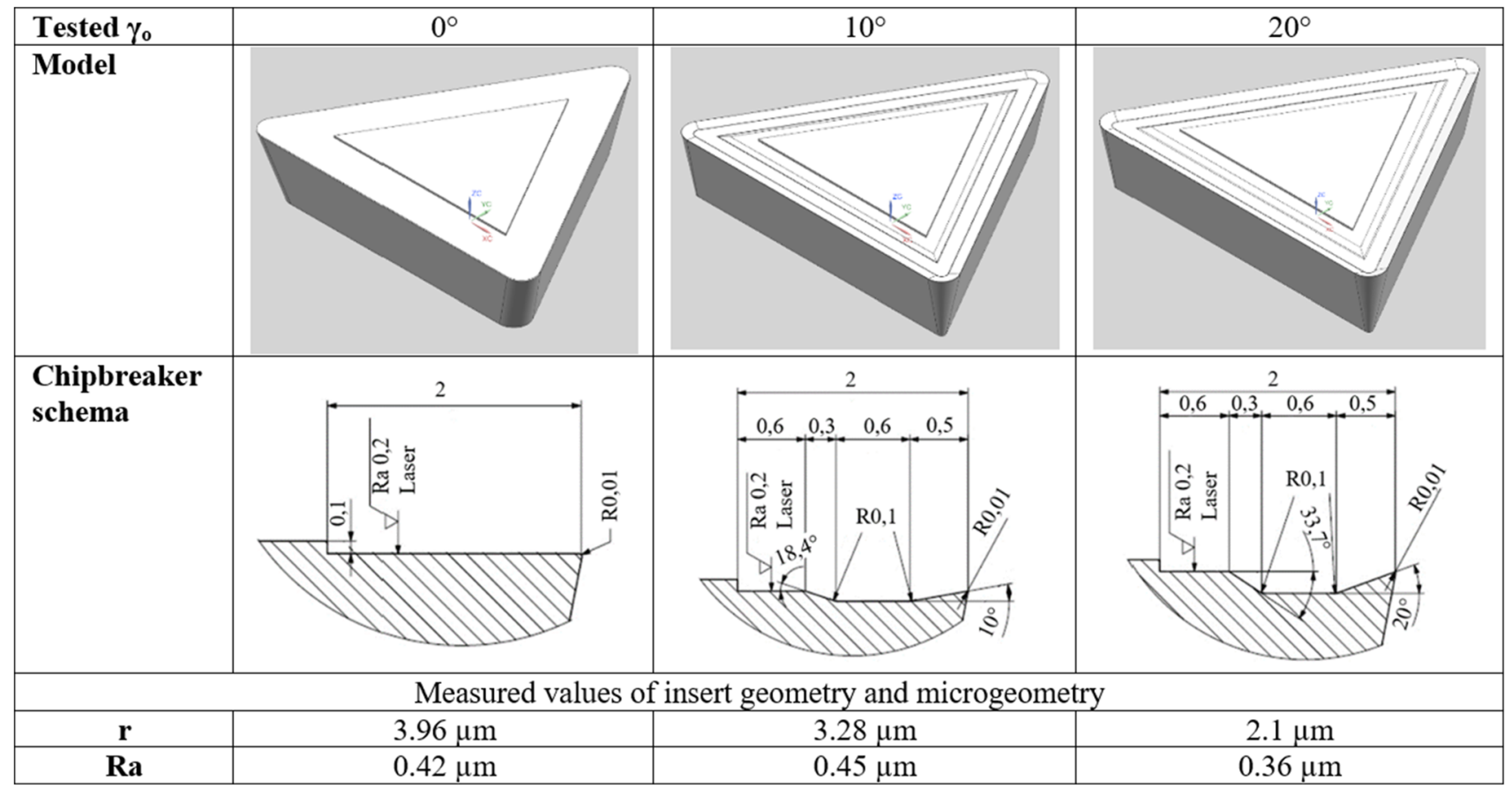


setup is shown in Fig. 2 and real setup is in Fig. 3. The workpiece was clamped in the chuck and supported by the tailstock. Both sides of the workpiece were insulated from the machine tool by special tape, and the cutting tool was likewise insulated from the dynamometer. The compensation wire used to elongate the cutting tool branch was connected to a DAQ NI 9232 module (National Instruments). The rotary part of the workpiece branch was firstly connected to a Mercotac Type 205 slip ring, which was clamped in a special PETG 3D printed interface and mounted to the through-hole in the spindle. A software application was programmed in Labview software for the acquisition and storage of the measured data.

Before the spindle was spun, the cutting tool was set to the contact position with the workpiece. This closed the thermoelectric circuit and made it possible to read the zero value of the EMF. Then the spindle was spun, but without feed to remove a thin layer which remained from previous machining (Fig. 4). Prior to this preparation, a hump was observed at the beginning of the measured signal and for a short and quick measurement it would have affected the shape of the EMF signal significantly. The measurement under the selected cutting conditions started after the spindle had been rotating for a few seconds. The resultant EMF was calculated by subtracting the average measured EMF value from the EMF zero value.

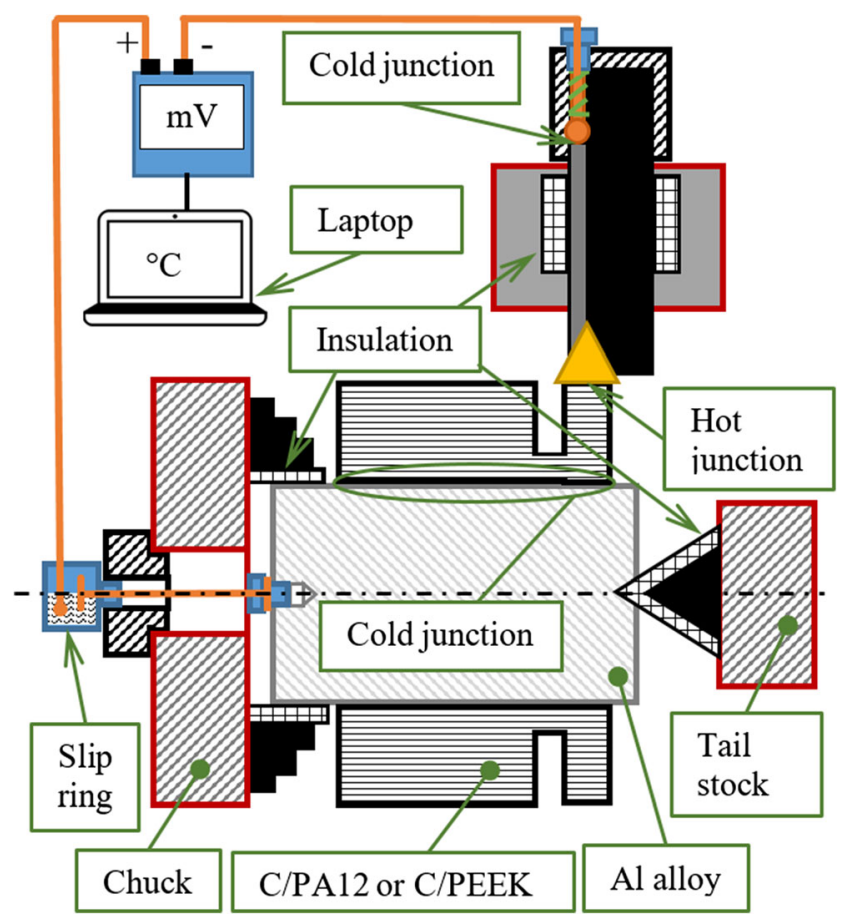

Fig. 2 Schematic design of experiment for measuring EMF to identify cutting temperature

\subsection{Process of calibration}

The calibration process was performed using a butadiene torch flame. The flame was adjusted to the position in front of the conjunction of the tool and workpiece and thermocouple K. EMF and temperature were detected simultaneously by an ALMEMO measuring station from AHLBORN. When the calibration temperature reached approximately $800^{\circ} \mathrm{C}$, the measurement was interrupted, the flame was turned off and cooling took place spontaneously. Almost the same circuit that was used for calibration was used for the experimental measurements. It was not possible to use this design because the carbide rod disconnected from the insert due to the extensive heat from the torch. Thus, the insert was removed from the cutting tool branch of the circuit. A workpiece and cutting tool branch were connected to the ALMEMO as well as the thermocouple (type K) for the temperature measurement (Fig. 5). The calibration was repeated five times for statistical evaluation of the measured data and uncertainty evaluation.

\subsection{Evaluation of the chips}

Chips were collected during machining and compared to one another for heat damage investigation. Subsequently, several typical chips for each test were photographed using an optical microscope by LIM (Laboratory Imaging s.r.o.) with up to 50 times optical zoom (Fig. 6). Photographs of the tool side and workpiece side of the chips were taken with the microscope. Macro photographs of the chips were taken with a Canon EOS 550D digital camera.

\subsection{Evaluation of machined surface}

The machined surface could be affected by heat. The machined surface was evaluated by optical method and by surface roughness measurement. Photographs were taken with a digital optical microscope from LIM. Surface roughness was measured with a Surtronic 3+ portable, self-contained instrument (Fig. 7). Surface roughness was measured perpendicular to the cutting velocity vector. Ra parameter of surface roughness was evaluated five times in each run of the experiment. The surface deformation demonstrates the influence of the cutting conditions of heat and force.

\subsection{Investigation of the structural changes to the workpiece}

A structural change can be observed in the polymers when they are affected by heat. Structural changes are manifested by a change in the melting point value. DSC (differential scanning calorimetry) was chosen for evaluation of the melting point for the composites C/PA12 and C/PEEK after affecting by heat in regards to machining. A NETZSCH STA 409 
Fig. 3 Setup of experiment on the turning centre

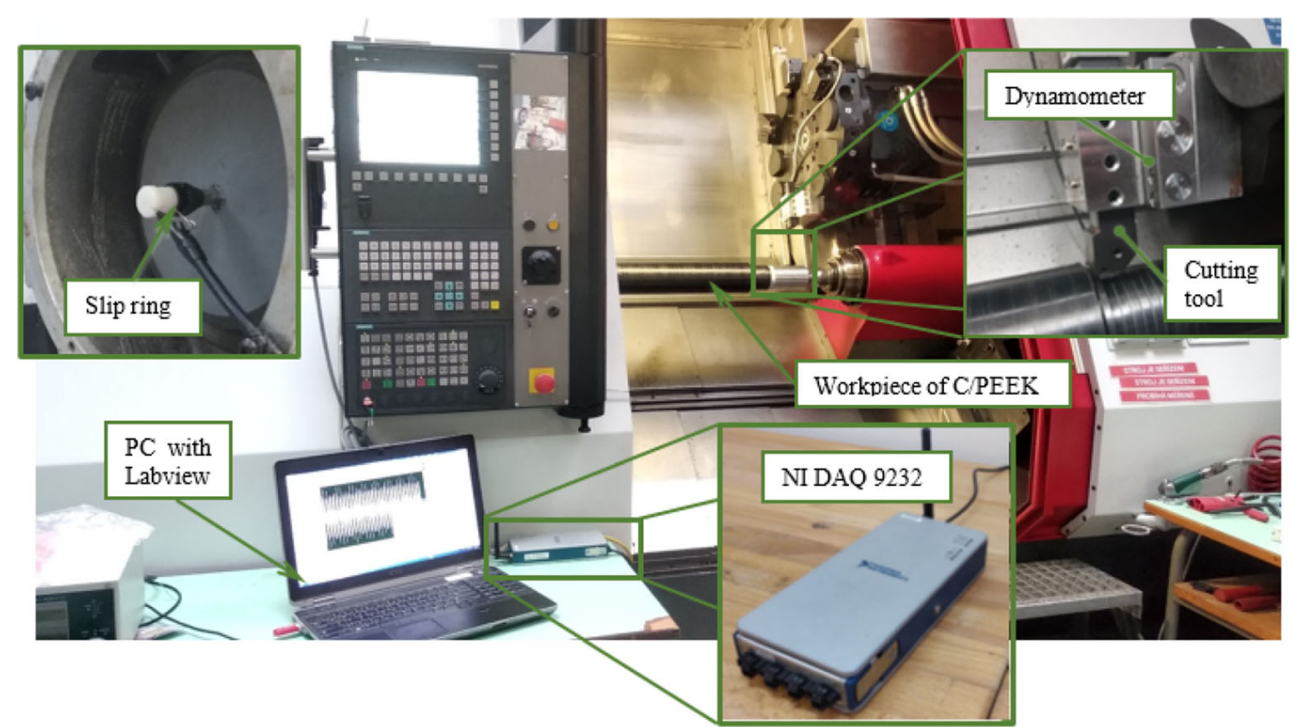

PG LUXX thermal analysis device was used. A heating rate of $10{ }^{\circ} \mathrm{C} / \mathrm{min}$ was selected per the EN ISO 11357-1 standard. The real cooling rate was 3 to $2{ }^{\circ} \mathrm{C}$.

The differential scanning calorimetry (DSC) method is suitable for revealing the thermal history of the tested polymer. In this case, we examined whether any change to the crystalline structure had occurred under high temperature. This would be manifested by a change in the crystallization temperature of the polymer. It was necessary to obtain one specimen whose temperature was not affected by machining, one unmachined specimen and one with a high measured temperature. In the reference [42], Pomerenke described the possibility of using this method for the analysis of crystallization temperature changes in polymers after heating.

\subsection{Measurement}

The experiment design had five cutting velocity levels ranging from 100 to $300 \mathrm{~m} / \mathrm{min}$ and two feed values of $0.15 \mathrm{~mm}$ and $0.3 \mathrm{~mm}$. Cutting tools with three different rake angles, namely

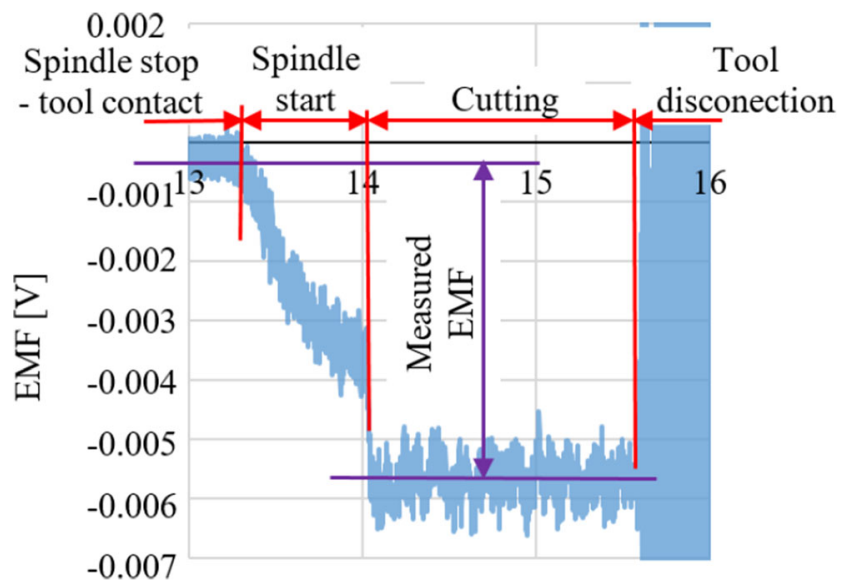

Fig. 4 Evaluation of the EMF signal principle $5^{\circ}, 15^{\circ}$ and $25^{\circ}$, were tested. The experiment was performed in three repetitions. Moreover, the number of repetitions was increased to 6 for specific combinations of parameters $\left(v_{c}=\right.$ $100 \mathrm{~m} / \mathrm{min} ; f=0.15 \mathrm{~mm} ; \gamma_{o}=5^{\circ}$ ) to express measurement uncertainty. The values of these parameters are highlighted in Table 3. These values were chosen in order to obtain a better quality of the EMF record, which was slightly easier to read for smaller cutting conditions than for higher ones due to the dynamic effects of the cutting process.

\section{Results and discussion}

\subsection{Calibration of the thermocouple and uncertainty of measurement assessment}

Taking measurements with a tool-work thermocouple enables documentation of the cutting temperature - i.e. the mean of the temperatures in all contact joints between the cutting tool and workpiece during machining. It is the temperature not only on the cutting edge but also on the small part of the rake and clearance face depending on the cutting edge engage conditions. Cutting temperature is the highest temperature which can be measured during machining. The main disadvantage of this measurement method is that it requires calibration, which is complicated for polymeric composites due to the low matrix melting point and it was a significant source of uncertainty. Butadiene torch calibration was chosen mainly because it allowed use of an unchanged workpiece and cutting tool without requiring manufacture of another calibration setup. The main setup used during the experimental machining was changed only slightly and the indexable insert was removed. This setup gave a stable EMF signal under intensive torch heating and the thermoelectric circuit was stable. The difference between the indexable insert and the carbide rod was 
Fig. 5 Calibration of T700 - WCCo rod thermocouple: schematic (left), photo of actual setup (right)
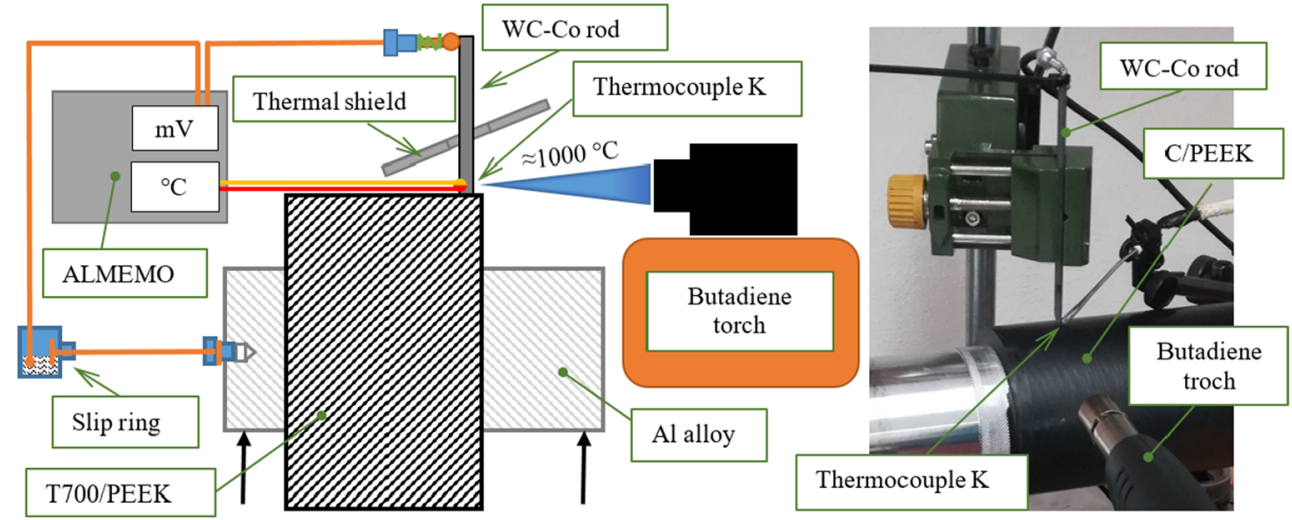

neglected due to the similarity of the chemical composition of the two types of carbide and became the uncertainty of the measurement. The temperature on the measured part was gradually increased up to $800{ }^{\circ} \mathrm{C}$ on the $\mathrm{C} / \mathrm{PEEK}$ composite. The tested specimen was locally deformed by this intense heat.

The same calibration curve was valid for C/PA12 and $\mathrm{C} / \mathrm{PEEK}$ also because both have the same type of carbon fibres and volume. The measured data were interspersed by polynomial function regression analysis and then prediction intervals were defined for evaluation of uncertainty. The calculated equation of the calibration curve had a determination coefficient of 0.997 (Fig. 8). That is proof that the established model fits measured data well. The calibration curve equation that was obtained for the calculation of the cutting temperature $(\Theta)$ is presented below by Eq. (1).

$$
\begin{array}{r}
\Theta=-0.0234 \cdot E M F^{5}+0.6089 \cdot E M F^{4}-6.1079 \cdot E M F^{3} \\
+26.332 \cdot E M F^{2}+48.768 \cdot E M F+26.714
\end{array}
$$

The measurement uncertainty is the range of values which may be assigned to the measured values and it should be

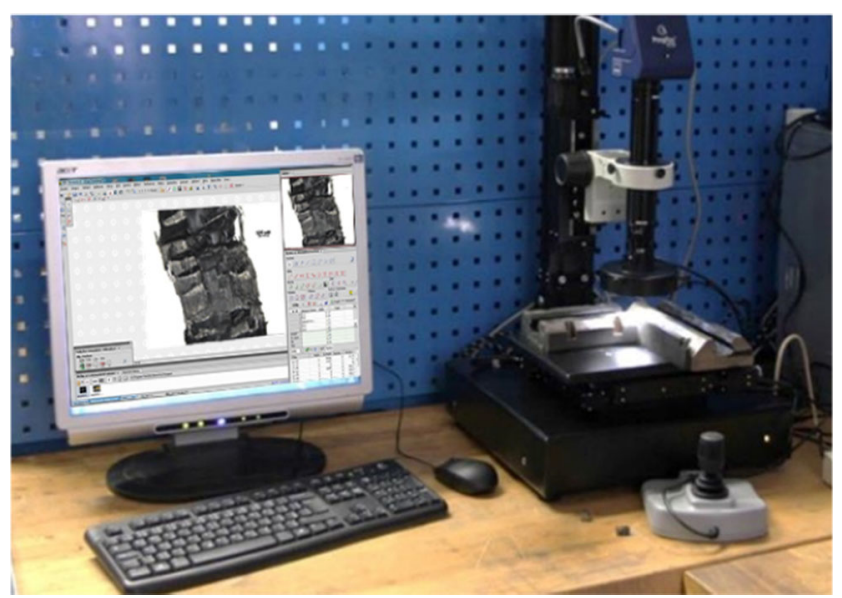

Fig. 6 LIM microscope - chips and surface measurement defined for each new measurement setup. The uncertainty of the calibration curve was given by the width of the prediction interval (PI) in which the value of the measured cutting temperature is correct and may be identified with the given EMF value with $95 \%$ probability. The width of the prediction interval was on average $\pm 14.52{ }^{\circ} \mathrm{C}$. Uncertainty from other sources was added to this prediction interval. The only uncertainty source was the ALMEMO 5690-2CPU in this case, specifically the uncertainty coupled with the voltage measurement error and uncertainty coupled with the error of the temperature measurement measured with a K-type thermocouple. The resulting calibration uncertainty was $u_{b}=14.59{ }^{\circ} \mathrm{C}$ and this was not a relevant difference from the prediction interval alone.

Uncertainty type A is the uncertainty calculated directly from a number of measurements and is equal to the corrected sampling standard deviation. The determination of this type of uncertainty was performed from an experiment with an increased number of replications under cutting conditions $\left(v_{c}=\right.$ $\left.100 \mathrm{~m} / \mathrm{min} ; f=0.15 \mathrm{~mm} ; \gamma_{o}=5^{\circ}\right)$. The average temperature measured for C/PA12 was $324{ }^{\circ} \mathrm{C}$ with uncertainty $u_{a}=8.11$ ${ }^{\circ} \mathrm{C}$. The resulting uncertainty with calculated calibration measurement uncertainty was $u_{c}=16.69{ }^{\circ} \mathrm{C}$ for material C/PA12 for the given cutting conditions. The resulting description of uncertainty was $(323.88 \pm 16.69){ }^{\circ} \mathrm{C}$ for material C/PA12.

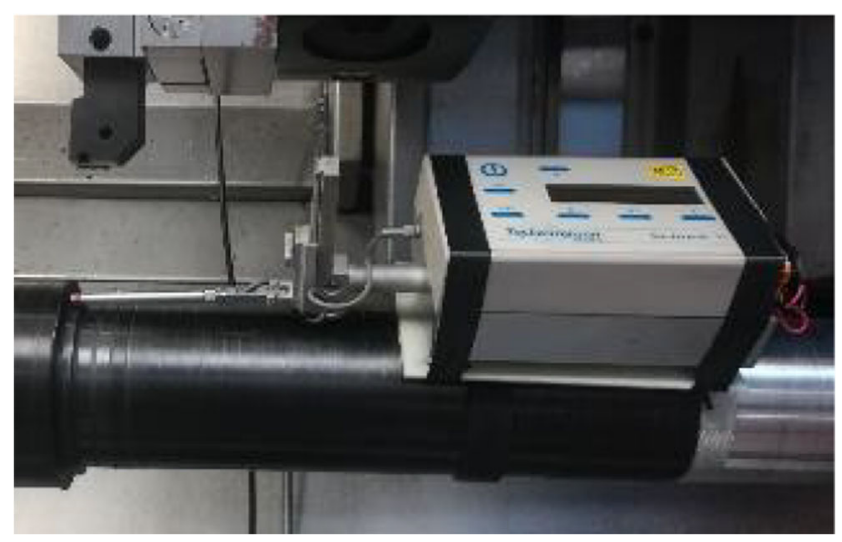

Fig. 7 Surtronic 3+ - Surface roughness measurement 
Table 3 Design of full factorial experiment — cutting parameters

\begin{tabular}{|c|c|c|c|c|c|c|c|}
\hline \multirow[t]{2}{*}{ Parameter/factor } & & & \multicolumn{5}{|c|}{ Level } \\
\hline & & & 1 & 2 & 3 & 4 & 5 \\
\hline Cutting velocity & $\begin{array}{l}\mathrm{m} / \\
\mathrm{min}\end{array}$ & $v_{c}$ & 100 & 150 & 200 & 250 & 300 \\
\hline Feed per revolution & $\mathrm{mm}$ & $f$ & 0.15 & 0.3 & & & \\
\hline Rake angle & $\circ$ & $\gamma_{o}$ & 5 & 15 & 25 & & \\
\hline
\end{tabular}

The average temperature measured for $\mathrm{C} / \mathrm{PEEK}$ was $530^{\circ} \mathrm{C}$ with uncertainty $u_{a}=7.25^{\circ} \mathrm{C}$. The resulting uncertainty was $u_{c}=16.29^{\circ} \mathrm{C}$ and the resulting description of uncertainty was $(530.28 \pm 16.29){ }^{\circ} \mathrm{C}$ for the $\mathrm{C} / \mathrm{PEEK}$ material.

\subsection{Evaluation of the cutting temperature measurement}

Cutting temperature was measured almost always above the melting point of tested matrices. The cutting temperature was nearest to the melting point when C/PA12 was measured (Figs. 12, 13, 14 and 15). Relative increment of cutting temperature above melting point was only a little bit different for both tested materials. This high temperature should affect both the machined surface and the chips. For this reason, the machined surface and chips were measured and evaluated. The results of these measurements are described in the following text.

The measured values were analysed using the ANOVA method. Statistically significant parameters were revealed and then used to determine the predictive mathematical model for calculation of the cutting temperature. It is possible to reject the null hypothesis about equal variances at a

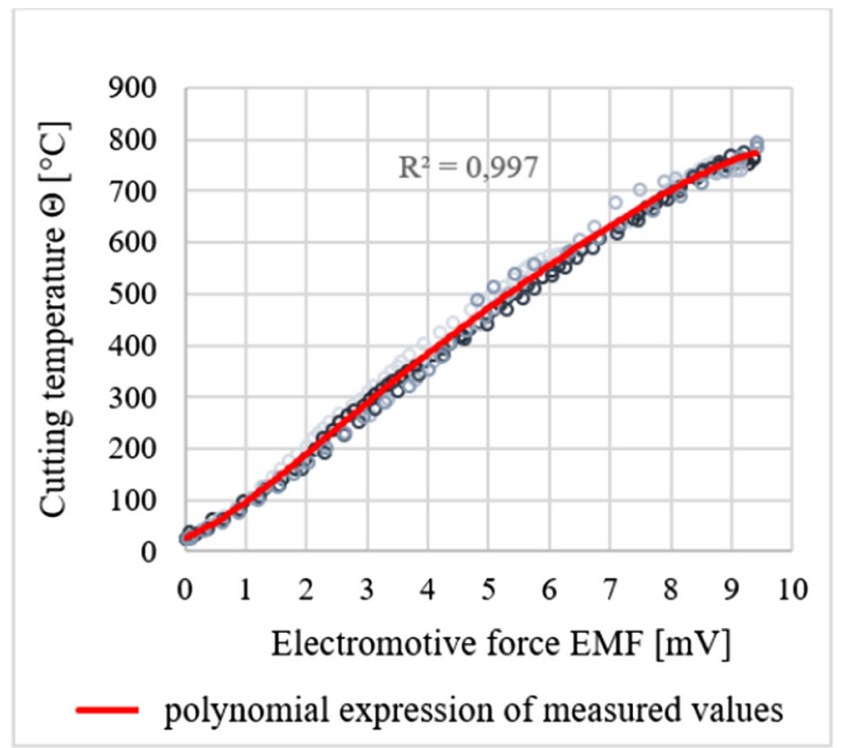

Fig. 8 Calibration curve T700 - WC-Co for cutting temperature significance level of $\alpha=0.05$ from the results of $\mathrm{p}$-values for control factors $v_{c}$ and $\gamma_{o}$ for both tested materials (Table 4 and Table 5). That means that the only statistically insignificant factor was feed. Control factors $v_{c}$ and $\gamma_{o}$ are almost equal in statistical significance on the basis of the value F.

In C/PA12 machining, the most important factor was the cutting speed, but the difference in $\mathrm{F}$ value for the cutting speed and the rake angle was relatively small. The opposite result was found for C/PEEK, where the cutting speed had a smaller value of $\mathrm{F}$ than the rake angle. However, the difference between them was again small. A higher rake angle leads to less deformation in the primary cutting zone and a lower cutting temperature. The cutting speed has the most significant effect on the cutting temperature and the results of this study were consistent with this well-known fact.

The main effect plot for the cutting temperature mean describes the behaviour of temperature with the changing control factor (Fig. 9). It is possible to compare the two tested materials at once. C/PA12 generated a cutting temperature about $201{ }^{\circ} \mathrm{C}$ lower on average. The cutting temperature grew with cutting velocity nonlinearly for both the tested composite materials. This dependence was similar to the power function which was used to design the predictive model. Contrarily, the increasing rake angle decreased the cutting temperature linearly. The feed had no influence and remains almost horizontal in the diagram.

The measured cutting temperature was almost always above the melting point of the tested matrices. The cutting temperature was closest to the melting point when C/PA12 was measured, but the ratio of the cutting temperature and melting point was almost identical for the two materials. The relative increment of the cutting temperature above the melting point was only slightly different for each of the tested materials.

A recommendation might be to decrease the cutting velocity at first when the thermal defects occur. The rake angle was also statistically significant. The cutting temperature

Table 4 Results of ANOVA test for C/PA12 composite

\begin{tabular}{llllllll}
\hline Source & DF & Seq SS & Adj SS & Adj MS & $\begin{array}{l}\text { P } \\
(\%)\end{array}$ & F & p-value \\
\hline$v_{c}$ & 4 & 73309 & 72143 & 18036 & 65.1 & 88.65 & 0 \\
$f$ & 1 & 177 & 43 & 43 & 0.2 & 0.21 & 0.648 \\
$\gamma_{o}$ & 2 & 33084 & 33084 & 16542 & 29.3 & 81.3 & 0 \\
Error & 30 & 6104 & 6104 & 203 & 5.4 & & \\
Total & 37 & 112673 & & & & & \\
\hline
\end{tabular}

$D F$ degrees of freedom, $S e q S S$ sequential sum of squares, $A d j S S$ adjusted sum of squares, Adj MS adjusted mean squares - variance around fitted value, $P(\%)$ percentage of contribution, $F$ F-value (test static), $\mathrm{p}$-value (probability) 
Table 5 Results of ANOVA test for C/PEEK composite

\begin{tabular}{llllllll}
\hline Source & DF & Seq SS & Adj SS & Adj MS & $\begin{array}{l}\text { P } \\
(\%)\end{array}$ & F & p-value \\
\hline$v_{c}$ & 4 & 50393 & 50393 & 12598 & 61.7 & 135.39 & 0 \\
$f$ & 1 & 132 & 132 & 132 & 0.2 & 1.42 & 0.242 \\
$\gamma_{o}$ & 2 & 27920 & 27920 & 13960 & 34.2 & 150.03 & 0 \\
Error & 34 & 3164 & 3164 & 93 & 3.9 & & \\
Total & 41 & 81609 & & & & & \\
\hline
\end{tabular}

decreased with increasing rake angle. A greater rake angle effect was measured for C/PA12. The PA12 matrix was the softer of the two tested matrices and it was able to undergo bigger plastic deformation during chip formation. The area of primary plastic deformation decreased and inclined towards the rake face of the cutting tool and the change of primary plastic deformation was greater than for the PEEK matrix due to the ability of PA12 to deform most easily. A linearity of cutting velocity dependency on rake angle was observed for both tested materials. The feed per revolution was evaluated as statistically insignificant. Increasing the feed is one major way to increase productivity without the risk of thermal defects but only until delamination issues occur.

\subsection{Cutting temperature models}

As expected, the cutting temperature was most sensitive to cutting velocity. The power function was estimated for this dependence. This mathematical representation corresponded with practical measurement of other metallic materials. This corresponds with practical measurements and with metallic material machining theory as well. The increment of the cutting temperature with cutting velocity was smaller for C/PEEK than for C/PA12 due to the lower deformation ability of the PEEK matrix. The second very important parameter of the cutting temperature model was the rake angle. Feed, as the insignificant control factor, was not included in the model.

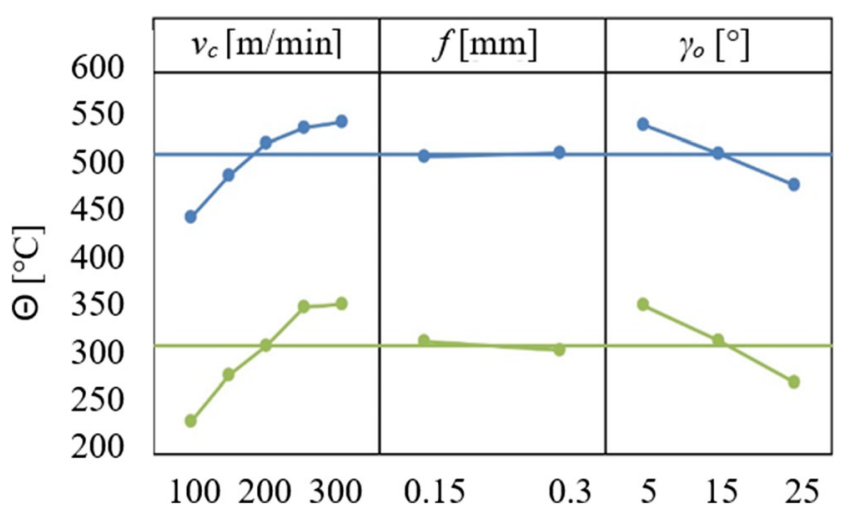

Fig. 9 Main effect plot for cutting temperature mean for C/PA12 (green) and C/PEEK (blue)
The model was determined for the most suitable mathematical interpretation with the best statistical fit. The equation was the same for both tested materials.

$$
=A^{*} v_{c}^{B}+\gamma^{*} C
$$

The coefficients for C/PA12 and C/PEEK were estimated by iterations in Minitab 16 software. The proposed parameters of the model equation are shown in Table 6 and Table 7.

The estimated coefficient $\mathrm{C}$ (for the rake angle) was very similar for both tested materials. The same coefficient was chosen for both materials $(\mathrm{C}=-3.5)$ due to the generalization of the model. The rest of the model coefficients were recalculated for these new entry conditions. The results of the newly estimated coefficients are shown in Table 8 and Table 9.

The model equation with the proposed coefficients for material C/PA12 was tested by the Lack-of-fit method (Table 10). As follows from evaluation of this test, there was no evidence demonstrating that this model did not fit the experimental data at a significance level of $\alpha=0.05$.

The model equation with the proposed coefficients for material C/PEEK was also tested by the Lack-of-fit method (Table 11). As follows from evaluation of this test, in this case as well there was not any evidence that this model did not fit the experimental data at a significance level of $\alpha=0.05$.

The measured data were compared with the model graphically. The predictive model respected the measured data and went through almost all measured points (Fig. 10 and Fig. 11) for material C/PA12 and also for C/PEEK (Fig. 12 and Fig. 13).

\subsection{Evaluation of chips and machined surface}

Neither the chips nor the machined surface showed any obvious thermal damage. Thermoplastic materials should become softer above the glass transition temperature due to elongation of polymeric chains. The high temperature in the shear zone could be a cause of the ribbon chips observed whenever the C/PA12 material was machined and C/PEEK on the small feeds and small rake angle. It was possible to get small segmented chips for C/PEEK (Table 12) when the feed was increased and the high rake angle was used. In this case, the

Table 6 Estimation of parameter for model - C/PA12

\begin{tabular}{lllll}
\hline Parameter & Estimate & SE & \multicolumn{2}{l}{ Estimate 95\% CI } \\
\cline { 4 - 5 }$A$ & 71.1927 & 8.71 & $(55.22 ;$ & $91.02)$ \\
\hline$B$ & 0.3152 & 0.22 & $(0.27 ;$ & $0.36)$ \\
$C$ & -3.9813 & 0.36 & $(-4.72 ;$ & $-3.24)$ \\
\hline
\end{tabular}

$S E$ standard error, $C I$ confidential interval 
Table 7 Estimation of parameter for model — C/PEEK

\begin{tabular}{lllll}
\hline Parameter & Estimate & SE & \multicolumn{2}{l}{ Estimate 95\% CI } \\
\cline { 4 - 5 }$A$ & 228.99 & 13.17 & $(203.47 ;$ & $257.32)$ \\
\hline$B$ & 0.17 & 0.011 & $(0.15 ;$ & $0.19)$ \\
$C$ & -3.32 & 0.272 & $(-3.79 ;$ & $-2.68)$ \\
\hline
\end{tabular}

chips sometimes curled themselves into flat spirals. If the radius of spiralling exceeded a particular diameter, the chips leaned on the unmachined surface and broke off. This phenomena was probably not affected by temperature because it seems to be independent of the cutting velocity. The chips are smoother on the tool side. The cracking of fibres was observable on the workpiece side of the chips. This was accompanied by observed waves of the matrix on the workpiece side of the chips which bond cracked chips. These waves occurred mainly under high cutting velocities.

The chips of the C/PA12 were all ribbon and snarled under various cutting conditions (Table 13). C/PA12 was machined closer to the melting point than C/PEEK. We observed smooth tool sides on the chips for all measurements. A cracking of the reinforcements was observed on the workpiece side of the chips. The chips broke into smaller ribbons when high feed and cutting speed was applied and a high rake angle was used. The combination of chip. The high rake angle together with the optional chipbreaker created shorter chips. The chips were curled in a smaller radius than when a smaller rake angle was used. If the chipbreaker was not used, the chip deformation would be smaller for a larger rake angle. Chip deformation for G/PEEK was evaluated by Davim and his results showed less chip deformation with higher rake angle [43]. No heat damage sign was found in the C/PA12 after optical measurement by the LIM microscope.

The machined surface was photographed with a microscope (Table 14). No negative effect of heat on the machined surface was observed, although the cutting temperature was higher in each run of the experiment than the melting point of the matrix. The machined surface was more affected in the case of C/PA12 after turning than for C/PEEK. The machined surfaces seemed to be slightly worse when the rake angle of

Table 8 Second estimation of model parameters - C/P12

\begin{tabular}{lllll}
\hline Parameter & Estimate & SE & \multicolumn{2}{l}{ Estimate 95\% CI } \\
\cline { 4 - 5 }$A$ & 67.52 & 8.1 & 52.78 & 86.05 \\
\hline$B$ & 0.32 & 0.02 & 0.28 & 0.37 \\
$C$ & -3.5 & & & \\
\hline
\end{tabular}

Table 9 Second estimation of model parameters - C/PEEK

\begin{tabular}{lllll}
\hline Parameter & Estimate & SE & \multicolumn{2}{l}{ Estimate 95\% CI } \\
\cline { 4 - 5 }$A$ & 232.125 & 12.86 & 207.29 & 259.76 \\
\hline$B$ & 0.169 & 0.011 & 0.15 & 0.19 \\
$C$ & -3.5 & & & \\
\hline
\end{tabular}

the cutting tool was small. The cutting conditions did not have any visible influence on the machined surface.

Photographs of the machined surfaces were supplemented by surface roughness measurements. Surface roughness was evaluated by Ra parameter and measurements were made perpendicular to the main cutting movement, which was the only usable direction for measurement in the machine tool. The measured surface roughness of C/PA12 was twice that of C/PEEK. The cutting temperature most likely melted spikes of roughness and made the surface smoother. The effect of surface roughness was also proven for C/PEEK but only to a limited extent. Variations of the measured data were higher than the differences between rake angle levels. A significant influence of the rake angle on the surface roughness was measured mainly for C/PA12 where the differences between the measurements were higher than for C/PEEK. The surface roughness increased with rake angle (Fig. 14 and Fig. 15). Only very small differences in surface roughness were observed when the cutting velocity was changed. It seemed that the difference between the minimum and maximum rake angle decreased when the cutting velocity was increased. However, it can be stated that the increase in cutting speed led to less surface roughness. This corresponds to the study published by Davim and Reis [44].

\subsection{Results of DSC structural changes measurement}

Three specimens were required to obtain DSC analysis: one unmachined specimen, the other machined but not affected by heat, and the third machined with heat. The first specimen was taken from the unmachined surface layer of the workpiece. The second and third specimens were chips taken under specific cutting conditions. Each of the specimen was burned in a calorimeter's heat chamber and the thermal energy required to raise the temperature was measured.

Table 10 Lack-of-fit evaluation for C/PA12

\begin{tabular}{llllll}
\hline Source & DF & SS & MS & F & P \\
\hline Error & 28 & 7547 & 269.541 & & \\
Lack of fit & 13 & 3376.52 & 259.733 & 0.93 & 0.545 \\
Pure error & 15 & 4170.64 & 278.042 & & \\
\hline
\end{tabular}


Table 11 Lack-of-fit evaluation for C/PEEK

\begin{tabular}{llllll}
\hline Source & DF & SS & MS & F & P \\
\hline Error & 28 & 4125.06 & 147.324 & & \\
Lack of fit & 13 & 2746.84 & 211.295 & 2.3 & 0.063 \\
Pure error & 15 & 1378.22 & 91.882 & & \\
\hline
\end{tabular}

After interpolation of the cutting temperature model, it was predicted that the unaffected machined specimen should be machined with a cutting velocity of approx. $10 \mathrm{~m} / \mathrm{min}$ for both tested polymeric matrices. This estimation could be inaccurate because this small value of the cutting velocity was very far from the selected and verified range of cutting velocities of the cutting temperature model. Up to this value of the cutting velocity, it should not matter what values of the rake angle and the feed rate are selected. The measured temperature should be below the melting point during turning. An experiment proved that the measured cutting temperatures were below the melting point for cutting conditions: $v_{c}=10$ $\mathrm{m} / \mathrm{min}, f=0.15 \mathrm{~mm}$ and $\gamma_{o}=5^{\circ}$. The measured cutting temperature was $85^{\circ} \mathrm{C}$ for $\mathrm{C} / \mathrm{PEEK}$ and $55^{\circ}$ for $\mathrm{C} / \mathrm{PA} 12$. The cutting temperature model overestimated by almost three times the value of cutting temperatures for both tested composites using the above mentioned cutting conditions. The other machined specimen was machined under a cutting velocity of $300 \mathrm{~m} / \mathrm{min}$. The temperature measured under this cutting velocity was far above the melting point for both specimens. The feed rate and rake angle remain the same as the previous specimen. In principle, three samples were measured by the DSC method to determinate the crystalline temperature during cooling from the high temperature. Crystallization temperatures of the machined specimens were compared to one another.

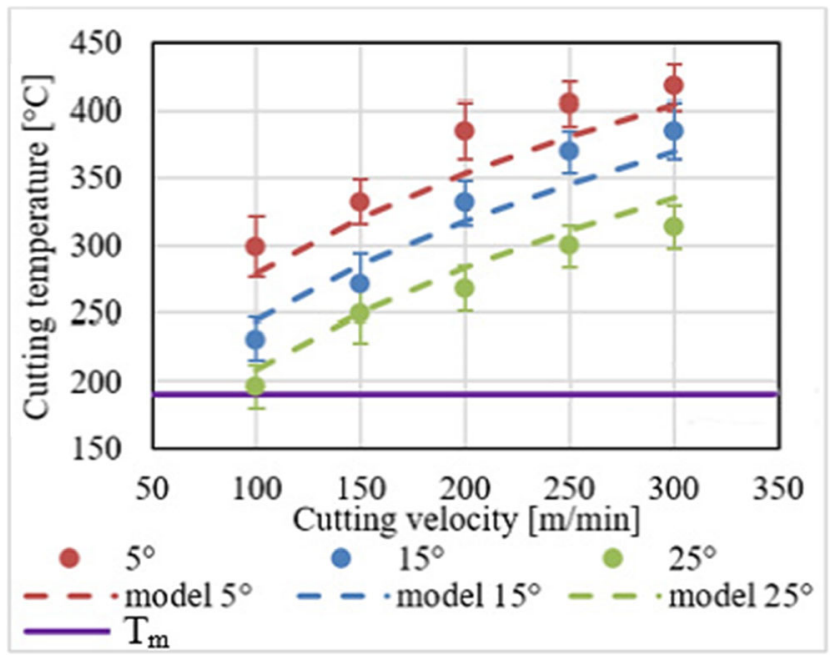

Fig. 10 Comparison of measured data and model function for C/PA12 ( $f$ $=0.15 \mathrm{~mm})$

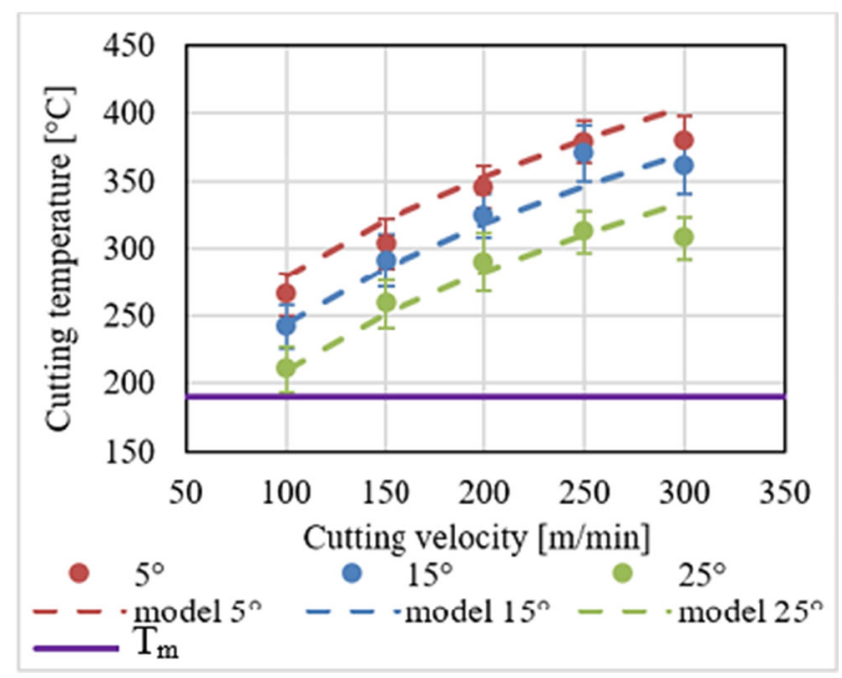

Fig. 11 Comparison of measured data and model function for C/PA12 ( $f$ $=0.3 \mathrm{~mm})$

The first C/PA12 unmachined specimen was heated to a temperature of $350{ }^{\circ} \mathrm{C}$ (green line, Fig. 16). When it had cooled, crystallization was observed at a temperature of 152 ${ }^{\circ} \mathrm{C}$. The crystallization temperature shifted to a lower temperature due to the change in the polymeric structure. The second specimen (red line, Fig. 16), machined at $v_{c}=300 \mathrm{~m} / \mathrm{min}$, was heated to the melting point and then cooled. The crystallization temperature was $158{ }^{\circ} \mathrm{C}$. The third specimen (blue line, Fig. 16) machined at $v_{c}=10 \mathrm{~m} / \mathrm{min}$ was tested in the same way as the second one. The crystallization temperature was the same as for the second speciment. This result means that there is no evidence of thermal effects on the specimen machinied at the $v_{c}=300 \mathrm{~m} / \mathrm{min}$ causing a change of the crystalline structure of the polymer in the entire volume of the test specimen. It is possible that the cutting temperature did not affect the bigger volume of the material from the cutting zone and the DSC method was unable to reveal the

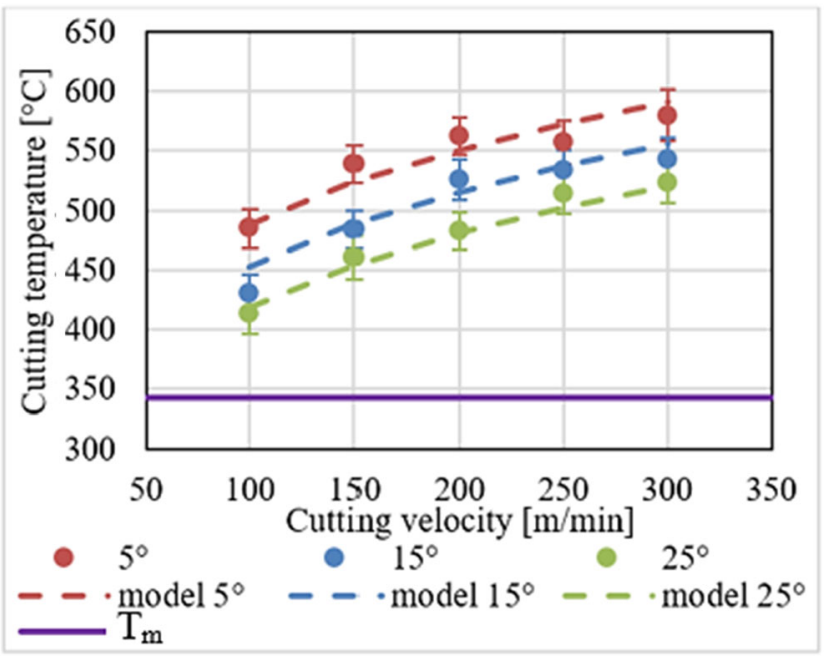

Fig. 12 Comparison of measured data and model function for C/PEEK $(f$ $=0.15 \mathrm{~mm}$ ) 


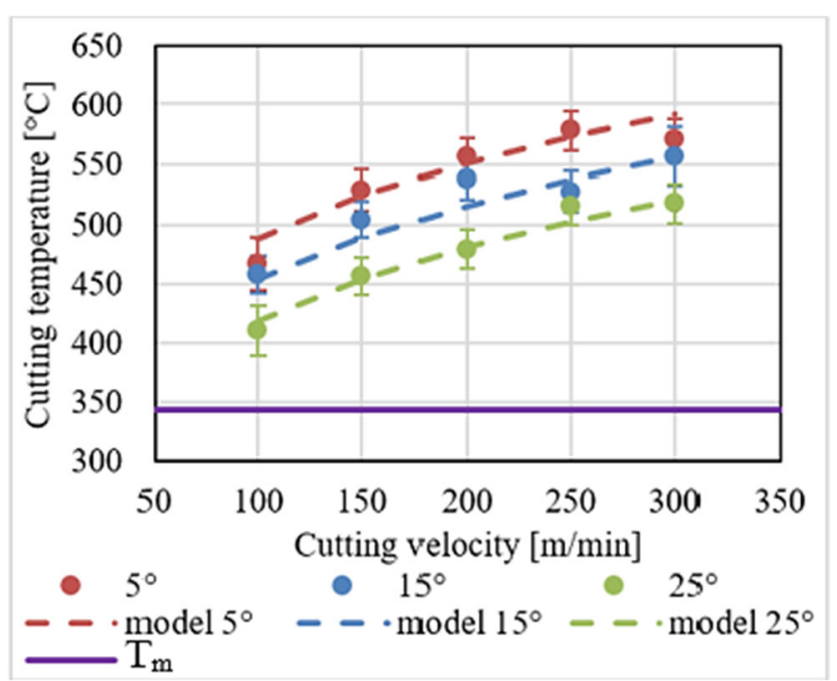

Fig. 13 Comparison of measured data and model function for C/PEEK $(f$ $=0.3 \mathrm{~mm}$ )

change of crystallization temperature. The second possibility is the inaccuracy of the tool-work for two-component composites. Only carbon fibres are the conductor of the EMF signal. However, carbon fibres have significantly higher mechanical properties than matrices. In our opinion, fibres defromation requires higher energy and very likely generates more heat during machining than the polymer matrix that binds fibres. However, the fibre volume was $55 \%$ and the thermal conductivity of the polymer could inhibited equaly conduction of the heat to the entire volume of the chip or machined surface. The resulting heat would then be less than the heat indicated by the measured temperatures. It was assumed that the total weight of the machined specimens was affected by heat. However, poor thermal conductivity of the polymers could cause the temperature of the contact points between the cutting tool edge and the front side of the chip to be higher than the back side of the chip. These unverified speculations could be the reason why the change in the crystalline structure was not detected in polmyers by DSC. An additional experimental investigation could be made for verifying this hypotesis in the future.

The C/PEEK material was tested by the DSC method in the same way (Fig. 17). The first unmachined specimen (green line, Fig. 17) was heated up to a temperature of $530^{\circ} \mathrm{C}$. That

Table 12 Comparison of C/PEEK chips under various cutting conditions

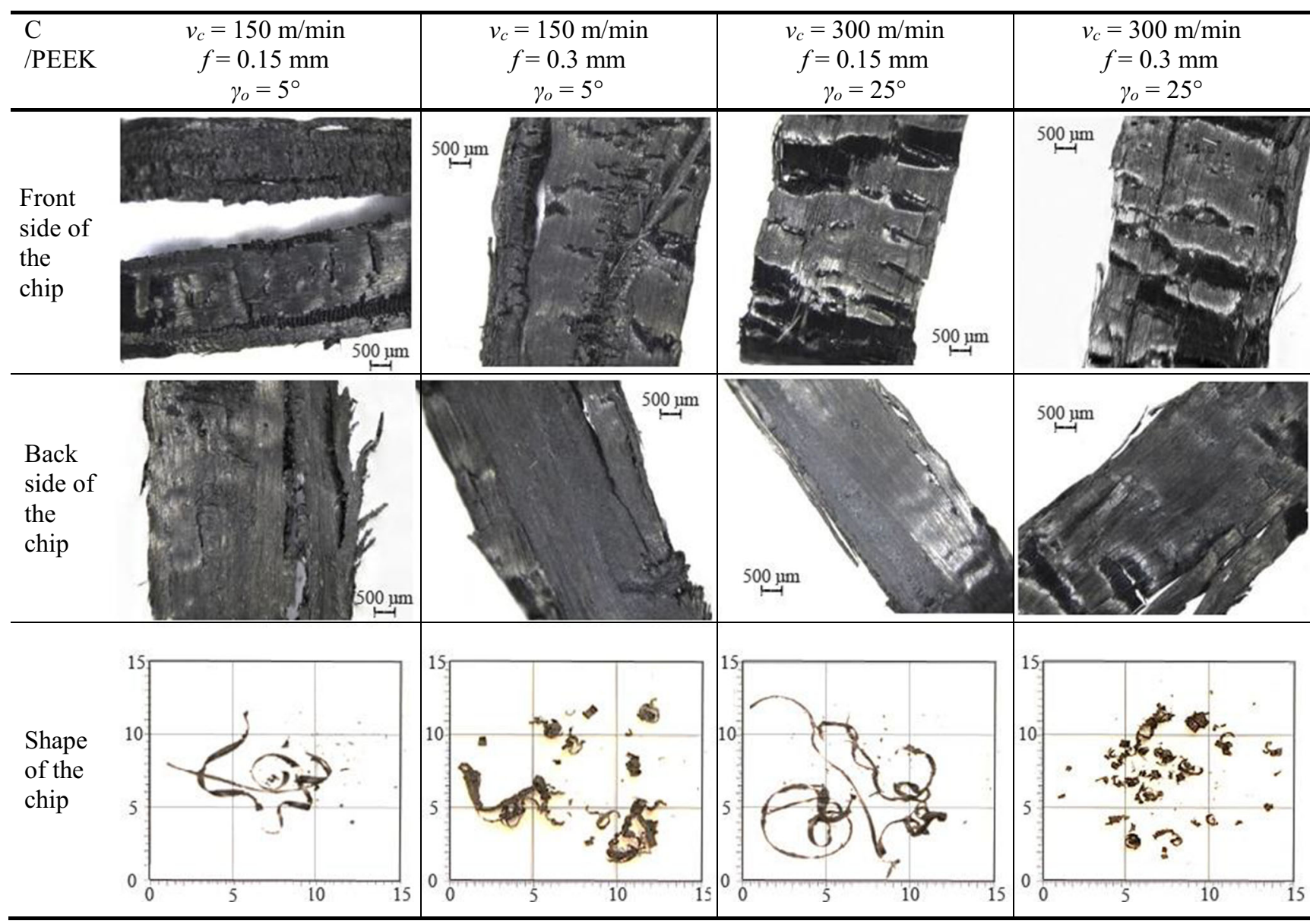


Table 13 Comparison of C/PA12 chips under various cutting conditions

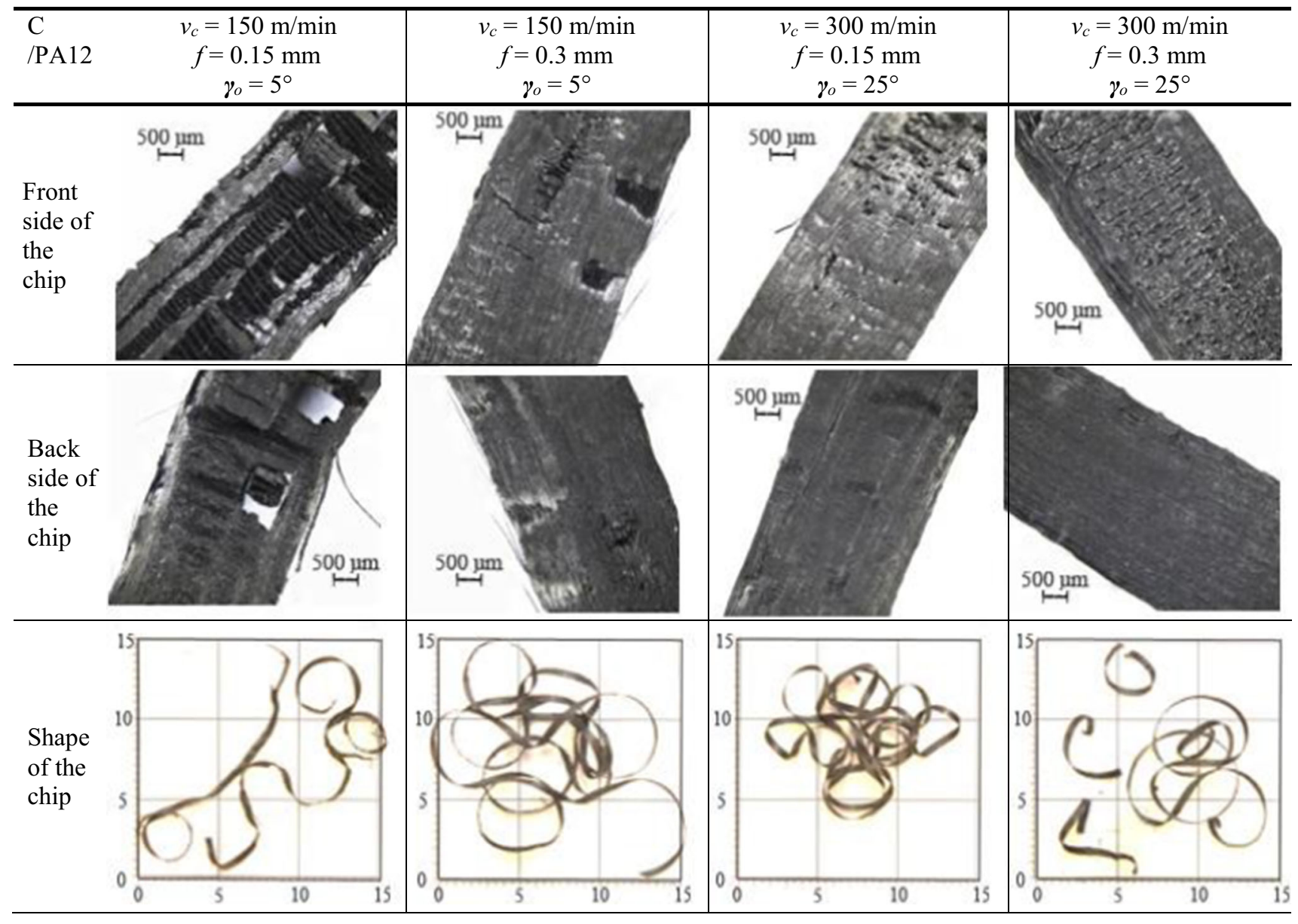

Table 14 Comparison of machined surface for C/PEEK and C/PA12 under different cutting conditions

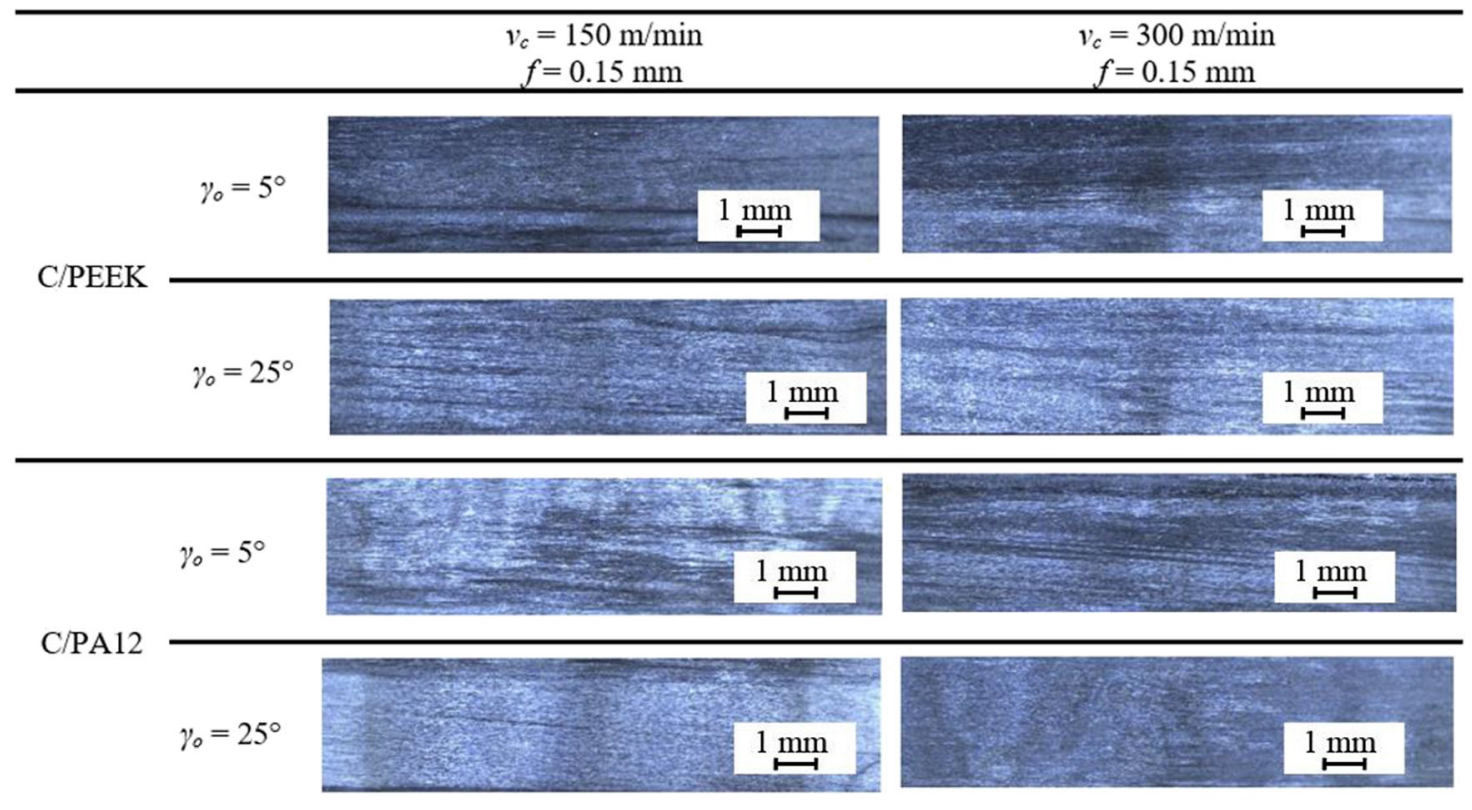




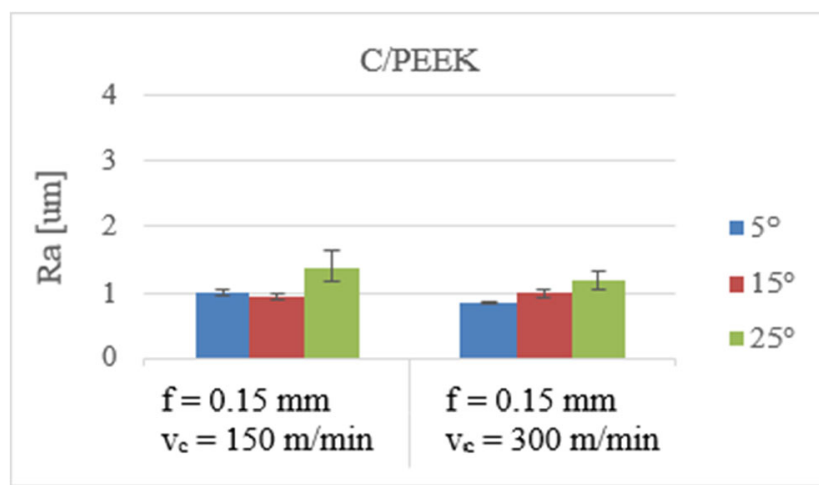

Fig. 14 Surface roughness comparison under various cutting conditions C/PEEK

was the highest measured temperature by the tool-work thermocouple. The crystallization temperature was not observed at all during cooling. The measurement was ended when a temperature of $200{ }^{\circ} \mathrm{C}$ was reached. The crystallization temperature should probably be lower. The crystallization temperature for both machined specimens was the same $-280^{\circ} \mathrm{C}$.

The DSC method did not reveal any evidences that chips were affected by the heat, which is consistent with [34] and [15] where SEM was used to the inspection of the heat effect on the composites. It is possible that the measured temperature affected only a small volume cut material, or the temperature measured by $\mathrm{T} 700$ - WC-Co thermocouple did not represent a real temperature in the cutting zone due to differences in the thermal properties of the reinforcement and the matrix. DSC method proved that the chosen composites were not heat affected by turning, although the glass transition temperature and also melting point were exceed.

\section{Conclusion}

In this paper, we proposed and verified a cutting temperature measurement method for carbon fibre reinforced plastic during turning by a tool-work thermocouple. Electrically conductive carbon fibres were used as a part of a thermoelectric

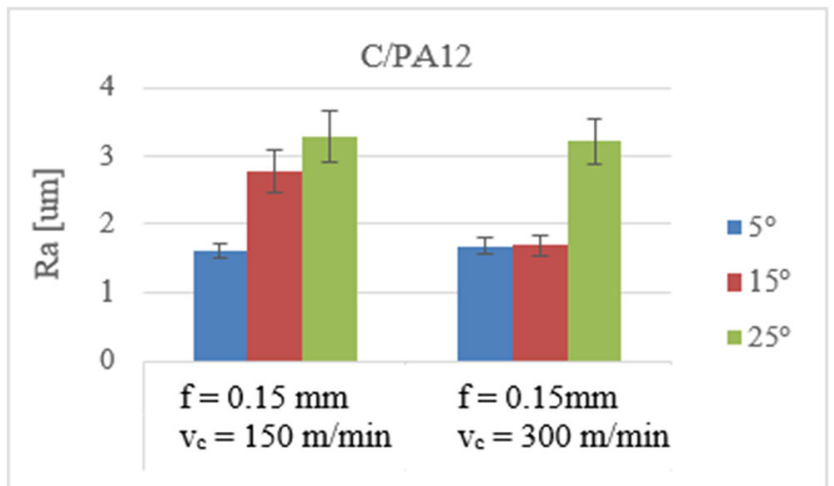

Fig. 15 Surface roughness comparison under various cutting conditions C/PA12

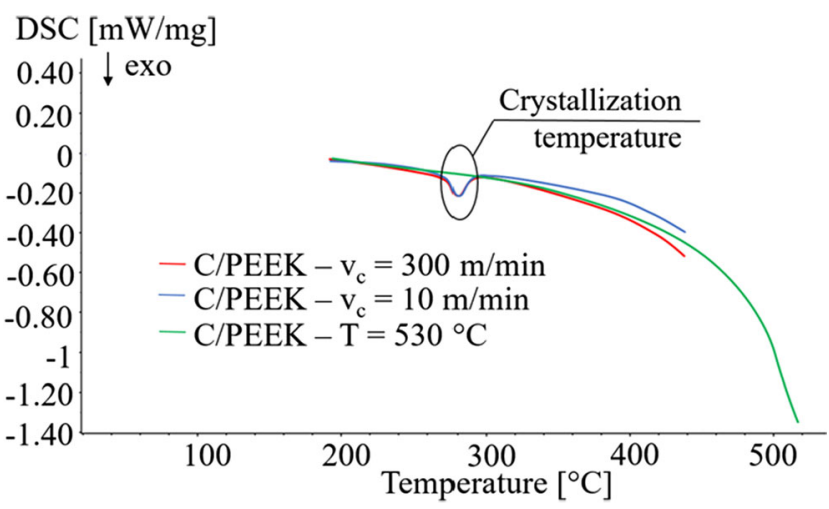

Fig. 16 Cooling curves for C/PEEK - DSC method

circuit. The calibration of the tool-work thermocouple was performed under a butadiene torch flame. This relatively well-known measurement method was used for the first time for this application. The main task was to determine the effect of cutting temperature on thermal damage of machined composites. The calibration of T700 - WC-Co was valid with the uncertainty of the measurement $\pm 15^{\circ} \mathrm{C}$. Work with the toolwork thermocouple was verified on a group of measurements for two CFRP materials, C/PA12 and C/PEEK. This measurement setting was relatively reliable and will be used in the future to further measurement of the cutting temperature of various metals and alloys with some improvements. The verification measurements led to these conclusions:

- The cutting temperature was dependent on the cutting velocity in the form of a power function in accordance with the theory of metal materials for both CFRPs.

- A positive influence on decreasing cutting temperature was observed with increasing rake angle.

- The measured effect of feed per revolution on cutting temperature was zero or very small.

Cutting temperature models for two composite materials have been proposed. The coefficients of the model equation were calculated from all measured data. These temperature

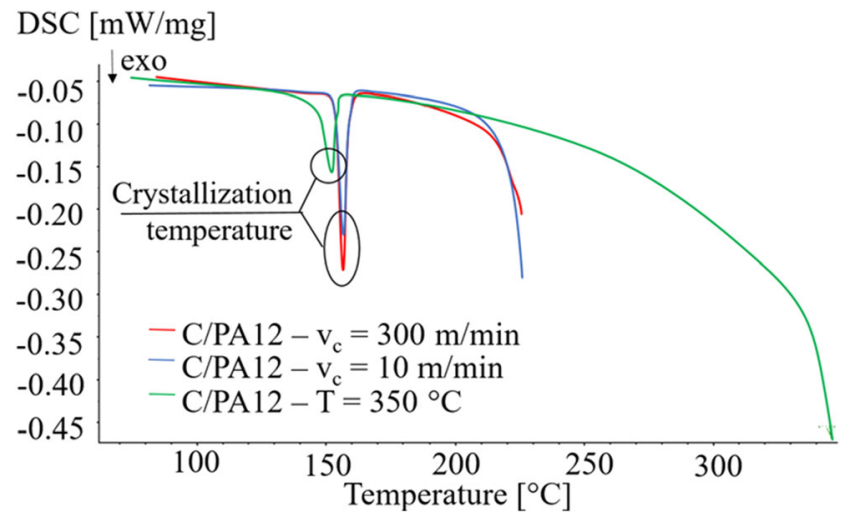

Fig. 17 Cooling curves for C/PA12 - DSC method 
models correspond to the measured data according to the statistical evaluation in the given range of the cutting conditions and the cutting tool geometry $\left(v_{c}=100\right.$ to $300 \mathrm{~m} / \mathrm{min}$ and $\gamma_{o}=$ $5^{\circ}$ to $25^{\circ}$ ). The cutting temperature model was designed and the equation coefficients were calculated from all of the measured data. This model was generalized for rake angle influence. Other coefficients were taken as material constants. The resultant model had verified conformity with the measured data according to the lack-of-fit test for both tested materials. These models can be used for practical application or for subsequent research. Future work will focus on the effect of cutting conditions on cutting forces for C/PA12 and C/PEEK composites.

There is no or only weak evidence of thermal defection for the machined surface and for the chips, although all measured values were above the melting point according to the toolwork thermocouple method of cutting temperature measurement. The DSC method was used to examine the change in crystallization temperature after previous heat treatment, and this method did not reveal the difference between heataffected and non-heat-affected specimens.

Additional measurements of surface roughness proved the negative influence of increasing rake angle. C/PA12 had a higher surface roughness than C/PEEK. The rake angle had a significant effect on both composites, but more significant on C/PA12 than on C/PEEK.

\section{Author contribution Not applicable.}

Funding This study is supported from the EU Operational Programme Research, Development and Education, and from the Center of Advanced Aerospace Technology (CZ.02.1.01/0.0/0.0/16_019/0000826), Faculty of Mechanical Engineering, Czech Technical University in Prague.

Data availability Not applicable.

Code availability Not applicable.

\section{Declarations}

Competing interests The authors declare no competing interests.

\section{References}

1. Sheikh-Ahmad J (2009) Machining of polymer composites. Springer Science+Business Media, LLC ISBN: 978-0-38768619-6

2. GVR Fiber Reinforced Polymer (FRP) Composites market analysis by fiber type (glass, carbon, basalt, aramid), by application (automotive, construction, electronic, defense), by region, and segment forecasts, 2018 - 2025. 10 2018. [Online]. Available: https://www. grandviewresearch.com/. [Access acquired 2 September 2020]
3. Cousins D, Suzuki YMRSJ, Stebner A (2019) Recycling glass fiber thermoplastic composites from wind turbine blades. J Clean Prod 209:1252-1263

4. Varatharajan R, Malhotra S, Vijayaraghavan L, Krishnamurthy R (2006) Mechanical and machining characteristics of GF/PP and GF/ Polyester composites. Mater Sci Eng B 132(1-2):134-137

5. Fleischer J, Teti R, Lanza G, Möhring MPH, Caggiano A (2017) Composite materials parts manufacturing. CIRP Ann Manuf Technol 67(2):603-626

6. Sheikh-Ahmad J, Dhuttargaon M, Cheraghi H (2017) New tool life criterion for delamination free milling of CFRP. Int J Adv Manuf Technol 92:2131-2143

7. Jia Z, Chen C, Wang F, Zhang C, Wang Q (2020) Analytical model for delamination of CFRP during drilling of CFRP/metal stacks. Int J Adv Manuf Technol 106:5099-5109

8. HIntze W, Cordes M, Koerkel G (2015) Influence of weave structure on delamination when milling CFRP. J Mater Process Technol 216:199-205

9. Kratas M, Gökkoya H (2018) A review on machinability of carbon fiber reinforced polymer (CFRP) and glass fiber reinforced polymer (GFRP) composite materials. Def Technol 14(4):318-326

10. Kwon B, Mai N, Cheon E, Ko S (2020) Development of a step drill for minimization of delamination and uncut in drilling carbon fiber reinforced plastics (CFRP). Int J Adv Manuf Technol 106:12911301

11. Wang C, Rakowski CKR, Greenwood D, Wale J (2017) Comparative studies on the effect of pilot drillings with application to high-speed drilling of carbon fibre reinforced plastic (CFRP) composites. Int J Adv Manuf Technol 89:3243-3255

12. Panchagnula K, Palaniyandi K (2018) Drilling on fiber reinforced polymer/nanopolymer composite laminates: a review. J Mater Res Technol 7(2):180-189

13. Xu J, Lin T, Chen M, Davim J (2020) Machining responses of highstrength carbon/epoxy composites using diamond-coated brad spur drills. Mater Manuf Process 36(6):1-8

14. Fu R, Jia Z, Wang F, Jin Y, Sun D, Yang L, Cheng D (2018) Drillexit temperature characteristics in drilling of UD and MD CFRP composites based on infrared thermography. Int J Mach Tools Manuf 135:24-37

15. Merino-Pérez J, Royer R, Ayvar-Soberanis S, Merson E, Hodzic A (2015) On the temperatures developed in CFRP drilling using uncoated WC-Co tools Part I: workpiece constituents, cutting speed and heat dissipation. Compos Struct 123:161-168

16. HIntze W, Harmann D, Shütte C (2011) Occurrence and propagation of delamination during the machining of carbon fibre reinforced plastics (CFRPs) - an experimental study. Compos Sci Technol 71(15):1719-1726

17. Voss R, Seeholze L, Kustner F, Wegener K (2017) Influence of fibre orientation, tool geometry and process parameters on surface quality in milling of CFRP. CIRP J Manuf Sci Technol 18:75-91

18. Patel P, Chaudhary V, Patel K, Gohil P (2018) Milling of polymer matrix composites: a review. Int J Appl Eng Res 13(10):7455-7465

19. Wang HSJ, Zhang D, Guo K, Li J (2016) The effect of cutting temperature in milling of carbon fiber reinforcedpolymer composites. Compos Part A 91:380-387

20. El-Hofya M, Soo SL, Aspinwall DK, Sim W, Pearson D, M'Saoubi R, Hardena P (2017) Tool temperature in slotting of CFRP composites. Procedia Manuf 10:371-381

21. Maalawi K, Abouelfotouh A, El Byoumi M, Ahmed K, Yehia A (2016) Design of composite pipes conveying fluid for improved stability characteristics. Int J Appl Eng Res 11:7633-7639

22. Ferreira J, Coppini N, Miranda G (1999) Machining optimisation in carbon ®bre reinforced composite materials. J Mater Process Technol 92 - 93:135-140 
23. Rahman M, Prakash RSJ, Tan D (1999) Machinability study of carbon fiber reinforced composite. J Mater Process Technol 8990:292-297

24. Sreejith P, Krishnamurthy R, Malhotra S, Narayanasamy K (2000) Evaluation of PCD tool performance during machining of carbon/ phenolic ablative composites. J Mater Process Technol 104:53-58

25. Davim JP, Mata F (2008) Chemical vapour deposition (CVD) diamond coated tools performance in machining of PEEK composites. Mater Des 29:1568-1574

26. Mata F, Gaitonde V, Karnic S, Davim J (2009) Influence of cutting conditions on machinability aspects of PEEK, PEEK CF 30 and PEEK GF 30 composites using PCD tools. J Mater Process Technol 209:1980-1987

27. Mata F, Beamud E, Hanafi I, Khamlichi A, Jabbouri A (2010) Multiple regression predictionmodel for cutting forces in turning carbon-reinforced PEEK CF30. Adv Mater Sci Eng 2010:1-7

28. Dold C, Henerichs M, Bochmann L, Wegener K (2012) Comparison of ground and laser machined polycrystalline diamond (PCD) tools in cutting carbon fiber reinforced plastics (CFRP) for aircraft structures. Procedia CIRP 1:184-189

29. Davies M, Ueda T, M'Saoubi R, Mullany B, Cooke A (2007) On the measurement of temperature in material removal processes. CIRP Ann 56(2):581-604

30. Kerrigan K, Thil J, Hewison R, O’Donnell G (2012) An integrated telemetric thermocouple sensor for process monitoring of CFRP milling operations. Procedia CIRP 1:449-454

31. Wang H, Sun J, Li J, Lu L, Li N (2016) Evaluation of cutting force and cutting temperature in milling carbon fiber-reinforced polymer composites. Int J Adv Manuf Technol 82:1517-1525

32. Masek P, Zeman P, Kolar P, Holesovsky F (2019) Edge trimming of C/PPS plates. Int J Adv Manuf Technol 101:157-170

33. Sheikh-Ahmad JY, Almaskari F, Hafeez F (2019) Thermal aspects in machining CFRPs: effect of cutter type and cutting parameters. Int J Adv Manuf Technol 100:2569-2582

34. Yashiro T, Ogawa T, Sasahara H (2013) Temperature measurement of cutting tool and machined surface layer in milling of CFRP. Int J Mach Tool Manu 70:63-69

35. Santos MC, Machado AR, Barrozo MAS, Neto LM (2013) Influence of thermoelectric junctions on the electrical signals generated by the tool-workpiece thermocouple system in machining. Measurement 46:2540-2546

36. Ghodam SD (2014) Temperature measurement of a cutting tool in turning process by using tool work thermocouple. Int J Res Eng Technol 3(4):831-835

37. Ceau G, Popovici V, Croitoru S (2010) Researches about the temperature of the cutting edge in turning of unalloyed steel. UPB Sci Bull D: Mech Eng 72(3):14

38. Zhang X, Lu Z, Peng Z, Sui H, Zhang D (2018) Development of a tool-workpiece thermocouple system for comparative study of the cutting temperature when high-speed ultrasonic vibration cutting Ti-6Al-4V alloys with and without cutting fluids. Int J Adv Manuf Technol 96:237-246

39. Kaminise AK, Guimarães G, Bacci da Silva M (2014) Development of a tool-work thermocouple calibration system with physical compensation to study the influence of tool-holder material on cutting temperature in machining. Int J Adv Manuf Technol 73:735-747

40. Abdelaziz Y (2012) Precise temperature measurement using noble metal thermocouples. In: Su Y (ed) Noble Metals, IntechOpen, London, pp 207-220

41. Dhar N, Islam S, Kamruzzaman M, Ahmed T (2005) The calibration of tool-work thermocouple in turning steels.Proceedings of National Conference on Industrial Problems on Machines and Mechanisms (IPROMM-2005):459-466

42. Pommerenke K (2009) Quality assurance of polymers by thermal analysis. Chemagazin XIX(1):8-9

43. Davim J, Mata F (2006) Physical cutting model of polyetheretherketone composites. Mater Des 27:847-852

44. Davim J, Reis P (2004) Machinability study on composite (polyetheretherketone reinforced with $30 \%$ glass fibre-PEEK GF 30) using polycrystalline diamond (PCD) and cemented carbide (K20) tools. Int J Adv Manuf Technol 23:412-418

Publisher's note Springer Nature remains neutral with regard to jurisdictional claims in published maps and institutional affiliations. 